\title{
Driving system of university mathematics practice teaching system III:
}

\section{view of learning}

\author{
Xiaobo Liü, a \\ ${ }^{1}$ School of information engineering, Nanjing Xiaozhuang University, Nanjing, China \\ a4487758@qq.com
}

Keywords: university mathematics, practice teaching system, driving system; view of learning.

\begin{abstract}
If the university mathematics teaching is divided into theoretical teaching and practical teaching, so these two different types of teaching performed not only the teaching content and way, but also change the way of thinking. There must be differences into teachers view, curriculum view, learning view, knowledge view and other aspects of them two in nature.
\end{abstract}

\section{Introduction}

People have always studied learning problems. With the study deepening, social factors and individual psychological factors gradually become the focus, the development of the theory of psychology reveals the human learning mechanism, expand the learning function, it helps people understand and learn, and also was better instructed for teaching. At present, a transformation of teaching is from teaching centered to the learning centered. To improve the students' learning ability, is the main task of teaching. The teaching theory should be based on the learning theory as the basis and core to discussed knowledge learning, and be as a basis for teaching methods and teaching principles.

\section{“Insight learning” of Gestalt}

The so-called "insight learning" is suddenly realize what, or may be an "all or nothing" experience, or is the part experience. ${ }^{[1]}$ Insight has three characteristics: clearly grasping the core or essence of a situation; at least including an automatic unconscious process in part without inference steps by steps; the abruptness of obtaining solution. ${ }^{[2]}$ Visible, insight is instantaneous, full range and divergent thinking, is the most basic and effective way of thinking in all creative activities. Some creative activities are achieved by insight.

The first half of twentieth century, Gestalt psychology is a cognitive response to the dominant behaviorism learning theory. The contribution is putting forward insight learning for learning theory first, forming a unique view on thinking and problem solving, and discussing how to generate insight.

Insight learning emphasizes to provide guidance and discovery with the way of indication, it helps learners to recompose view, overcome the insufficient or incorrect views of the problem, is learning process with stimulation-organization-reaction, it needs the learners put their hearts into the learning, is a process involved in understanding and wisdom. Although insight is not predictable, but the long-term accumulation of knowledge is a prerequisite for insight generated. Teachers should help individuals save a lot of related professional knowledge in teaching, and lay the 
foundation for the realization of insight. Application oriented education is obvious, and there are a lot of tacit knowledge. Skill formation is emotional and rational unified perception process, it must rely on the students insight in the experience, continue to explore, acquire, and accumulate in practice, and form occupation ability.

\section{Learning view of constructivism}

Constructivism is a theory of sociology, with the deepening of studying psychology, psychologists gradually put it into its research field, and after the learning theories and behaviorism, and cognitive learning theory developed further, it is regarded as a revolution of study field in the 1990s. It has abandoned the original understanding of learning process based on copying knowledge, and goes towards psychological process of acquiring knowledge through the construction of significance, and gives the characteristics of social learning. Although many of the constructivists' understandings for learning are not the same, the research angles are not exactly consistent, but the basic views of treating knowledge and learning are consistent. They believe that knowledge is the individual internal through the activity, especially creative, formative, constructive activities, the formation of true knowledge personally. Constructivism emphasizes the students go into the classroom with existing experience and background, which is the inherent basis of the subjectivity of the students. This concept means that knowledge gained from neither subject, nor from the object, but the process of interacting subject of the students and the environment, going through assimilation or adaptation mechanisms into their cognitive structure, and reorganizing it. Knowledge could not exist in the form of the entity out of individual, and it only could be constructed by the learners' individual experience and background based on life.

Therefore, teaching should be student-centered, based on the original understanding of the structure of learners as the basis for construction of the new knowledge understanding, and it should fully respect the subjectivity of students and individual differences. In college mathematics teaching, teachers should comply with the laws of cognition, promote students' active learning in the modern way, and construct a good cognitive structure. Teachers should guide students to find the fixed idea of new knowledge from existing knowledge structure, identify the similarities and differences between the new concept and the original related concepts, establish relationship between the old and new knowledge, and form a new knowledge structure.

In the teaching activity, the teacher is the leading subject of designing, organizing and controlling the teaching, so using knowledge and teaching of teachers as the center to design and organize teaching becomes prone to behavior. From the teaching point and final purpose, students are the subject of study and development, teaching could not instead of learning, and teaching must promote science. It embodied in the teaching design, to adhere to the basic idea of "designing teaching for learning”, taking "learning organization" as the center to organize teaching. Especially for the cultivation of mathematics application consciousness and ability, it should pay more attention to the experience of students, create a learning environment conducive to knowledge construction, and help the students construct mathematics application effectively.

To enable the students to improve the understanding of the value of mathematics, they must be allowed to understand the process of mathematical research, the process of putting forward the problem from the reality or internal mathematics, the process of exploration and the discovery of constructing the mathematical model, the process of solving practical problems using mathematical form. For some important contents, it should reveal the actual background, revealing development process and essence of related mathematical concepts, mathematical ideas, and mathematical 
conclusions. For example, in geometry, through the establishment of coordinate system, it could transform the geometric problem into algebraic problems to solve. When explaining the concept of derivative, the teacher only gives the geometric meaning usually, if they could use the rate of change of thought to give the meaning in physics and economics combining with some examples, it could not only improve the students' interest, but also and training is more conducive to the mathematics application consciousness and ability.

From the angle of mathematical knowledge, the essence of "designing teaching for learning” is to construct the mathematical form of education, mathematics knowledge actually have three forms: one is the natural form which exist in the world, in fact also exists in the minds of students. The two is the academic form; it exists as a kind of knowledge system of mathematics. Three is a form of education; it is the connection between nature and academic form. It needs to emphasize this important role for the cultivation of practical skills of mathematics. It is essential to the student centered learning to organize teaching, reflect the students' subject status, and help students construct knowledge of mathematics and its application.

\section{Situational learning theory}

With the development of modern information technology taking intelligent multimedia computer and network technology as the core, the people's research on the cognitive mechanism of brain science, and the nature of learning especially on constructivism theory gradually in-depth study, so the situational learning theory was born, it reminds people to research on the learning theory of it gradually from sociology, anthropology, ecology and other different perspectives to explore, but also to learn how to make a new interpretation.

Situated learning is a meaningful theoretical system, first of all, the knowledge is constructed in the process of interaction with the environment and the individual, learners obtain the knowledge from the activity in situation, learning is understood as a whole social practice, and an integral part of creative social practice in the world. ${ }^{[3]}$

Secondly, situational learning integrated the social constructivism and anthropology, consider learning from the view of participation, this study is legitimate peripheral participation in community of practice, people not only gain knowledge and skills, but also formed a community member through the practice in reality, it is the "community of practice". Through the practice, the community not only transformed the significance of learning from the learner's individual construction as transfer to social participation as practitioners of learning, but also realized from the individual cognitive process concept to the social practice of the transfer, and the learning theory was made from obtaining passively to the active participation.

Finally, legitimate peripheral participation is central concept and basic features of situational learning theory. The "legitimate" refers to the extent of using resources of the community legitimately by learners with the increase of time and experience; "marginality" means that the learner could not fully participate in all activities, and just as the participants of some activities. Therefore learning of legitimate peripheral participation is not only an important way to get new membership, but also the key of learning process of growing from the new to the expert from.

Situational learning theory is the proof of further development of constructivism, it is helpful for us to reconsider the traditional teaching field, and recognize the essential characteristics of learning. The basic ideas and main features have important reference value for practical teaching in colleges and universities. 
Blanche Ford believed that "it should create a way to let the students 'learning in practice', and could receive feedback timely and refine the personal understanding of learning environment constantly". ${ }^{[4]}$ The scene of practical knowledge and working process knowledge decided this kind of knowledge depend on the representation of working situation. The situation concern the teacher is provided to their meaning construction of environment for the learners. Learning situation has difference with the actual working environment after all, teachers should select learning content close to the situation of reality in teaching, and create of professional situation which was consistent with the real situation of the occupation group, to make the students actively study and explore through the virtual or the simulation scenario, participate for observation, imitation, the chance to participate or make arrangements for the learners to practical work through legitimate peripheral, this part is an important transformation proficient way of the individual being from the participation by edge to practiced hand .

In teaching practice, there will be a lot of tacit knowledge, and it hided in the practice of community which was produced by knowledge, people and situations, therefore, it should pay special attention to the situation of design supporting tacit knowledge development, it made learners implied the tacit knowledge in the behavior model and the processing of events the emotion into their own activities through the "legitimate peripheral participation". In the method of practice teaching, it can take the project center or task oriented teaching method, in order to complete the task, members of community should both have the general cognitive ability, also need positive interaction, negotiation, communication and social skills of members, and individuals and the community which are from different cultures the background and with different aptitude of community take theory and practice, thinking and action strategies, in the collision process, they obtain knowledge, development ability, form values, and accelerate the social process of individual.

In the initiation of concept of situational learning, there are many teaching strategies, such as cognitive apprenticeship, anchored instruction, interactive teaching, cooperative teaching, and inquiry learning. Many ideas of situational learning broaden people's horizons, it not only conforms to the development of the times, but also plays an important role in the education reform especially teaching reform practice of application oriented university. The conception of learning put forward by it made people came from the shackles of traditional teaching view of teacher centered, textbook centered and classroom centered, promoted the renewal of teaching concept and change the way of students learning.

\section{Intelligence Theory}

Intelligent theory has attracted more and more attention of many scholars, it provides a new perspective for people to know the essence and types of intelligence. In particular, Gardiner's multiple intelligence theory and Sternberg's intelligence theory provide some support for the practice teaching.

Gardiner's theory of multiple intelligences recognize the individual differences of people, holding the point that a person's intelligence is multiple and open, only the field of difference, but not the merits of the points or the severity from each other. It pays attention to students' starting behavior and individual advantage, and emphasizes potential of students.

The theory of multiple intelligences is conducive to our understanding of the characteristics of education, and the development of the field practice teaching will also inject new vitality into the practice of teaching. Practical teaching is in line with the characteristics of applied talents training, 
which is the main channel to realize the development of students' potential and the development of their human personality.

The American scholar Sternberg put forward the "three element theory" of human intelligence in the middle of 1980s, that human intelligence can be understood from the three sub theory of the "situation of theory", the "sub component theory" and the "experience of theory". Situated sub theory relates to the individual reality of the external world and the content of the intellectual behavior. The composition of the sub theory investigate the psychological basis of the potential model of intellectual behavior, and associate with the individual's internal world. At the same time, the "experience of theory" relates to the internal and external world, cause the experience is a bridge linking the main internal psychological and external world. Intelligent behavior of specific individuals determined by the situation of the sub theory, must be in a certain level of experience, which can be considered intelligent behavior, and the practice of "intelligence" is an important part of it, which is a relatively independent intellectual form.

Ten years apart, Sternberg once again developed the theory of intelligence, putting forward the successful intelligence theory, which consists of three parts: analytical intelligence, creative intelligence and practical intelligence. The theory points that successful intelligence especially academic intelligence and practical intelligence is significantly different from traditional, academic intelligence in the traditional evaluation, and practical intelligence is closely related to daily life. The main feature is the need to identify the problem, the definition of the concept of fuzzy, the need to seek information, a variety of solutions, closely linked to daily life, and to actively participate in the investment. In the process of solving practical problems, the problem is often not known, so we should find the problem before solve the problem. Sternberg believes that tacit knowledge is an important form of practical intelligence.

Application oriented undergraduate education has the characteristics of productive and practical, and it is decided by the training of talents in addition to their academic intelligence, and practical intelligence is essential too. Experience is an important influence factor of practical intelligence. Therefore, we should play an active role in the development of intelligence as far as possible based on the understanding of students' previous experience. On the basis of taking the development of students' academic ability into account, more emphasis should be laid on the practical work and the practical ability of life. Establish the teaching system with the emphasis on developing students' practical intelligence, while based on the development of multiple intelligences, which is not only as the meaning that the education of applied universities should have, but also as a necessary quality of the students in the applied universities.

\section{Acknowledgement}

The teaching project of Nanjing Xiaozhuang University: Research on "university mathematics” practical teaching under the goal of training applied talents stage result. The project of reforming and developing significant and important problems during The 13th Five-year of Nanjing Xiaozhuang University: Research on "university mathematics" practical teaching under the goal of training applied talents in local undergraduate colleges and universities (2016XZGJ07) stage result. The sub-project of the Twelfth Five-year plan key project "Research on teachers' professional development” of National Teacher Research Fund of China: Research on "university mathematics” practical teaching (GJS1523125) stage result. 


\section{References}

[1] Margaret E. Gredler, Learning and teaching: from theory to practice, China Light Industry Press, p. 48, 2007.

[2] Zhang Furong, The basic theory and teaching practice of learning, People's Education Press, p. 24, 1991.

[3] J. Lafe, E. Wenger, Situated Learning: Legitimate Peripheral Participation, East China Normal University Press, p. 3, 2002.

[4] John D. Bransford, Ann L. Brown, How people learn: brain, mind, experience, and school, East China Normal University Press, p. 5, 2002. 